\title{
Tumour of the lowest probability
}

\author{
C. K. Adarsh, Ravi Kiran, Mallikarjun Patil
}

Department of Gastroenterology, St. John's Medical College Hospital, Bengaluru, Karnataka, India

\begin{abstract}
The diagnosis of neuroendocrine tumor, in general, seems to have increased in the recent years, most likely due to better diagnostic modalities. Ampulla represents an uncommon site for the occurrence of neuroendocrine tumor of gastrointestinal tract $(0.05 \%) .{ }^{[1]} \mathrm{A}$ carcinoid tumor at the ampulla has varied presentations. Here, we report this rare case of neuroendocrine tumor at the ampulla in a young female presenting as abdominal pain and improving after pancreaticoduodenectomy.

Key words Ampulla, neuroendocrine tumor, pancreaticoduodenectomy
\end{abstract}

\section{Introduction}

Neuroendocrine tumors of ampulla of Vater are considered to be indolent and of exceptional pathology. Relevant literature regarding the neuroendocrine tumor of ampulla is limited to case reports and case series. Presently, there is no standard care prescribed for neuroendocrine tumors of ampulla of Vater due to poorly defined natural history. Whipple's resection is the usual surgical treatment offered. Neuroendocrine tumors of the ampulla, though rare, can be diagnosed accurately and has a good prognosis.

\section{Case Report}

A young adult female of 45 years presented to our outpatient department with intermittent vague abdominal pain for 5 years which had increased in severity and periodicity since 2 months. There was a significant weight loss in the past 2 months. Her clinical examination was unremarkable with no evidence of icterus, lymphadenopathy, or organomegaly. Her upper gastrointestinal (GI) endoscopy

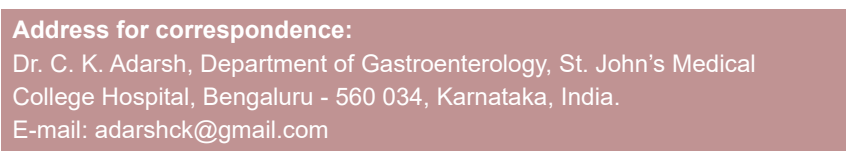

\begin{tabular}{|l|c|}
\hline \multicolumn{2}{|c|}{ Access this article online } \\
\hline \multirow{2}{*}{$\begin{array}{l}\text { Website: } \\
\text { www.jdeonline.in }\end{array}$} & Quick Response Code \\
\hline DOI: & \\
10.4103/0976-5042.189148 & \\
\hline
\end{tabular}

and ultrasound were normal. Her labs were normal except for mild elevation of serum alkaline phosphatase. Since her symptoms were persisting, further imaging was considered in the form of magnetic resonance cholangiopancreatography and computed tomography scan, which showed a homogenously enhancing soft tissue lesion, the size of which was $2.2 \mathrm{~cm} \times 2 \mathrm{~cm}$ arising from the junction of second and third part of the duodenum with adjacent lymph nodes [Figure 1]. Endoscopic ultrasound (EUS) was done for better characterization of the lesion [Figure 2]. Biopsy of the ampulla [Figure 3] was obtained, which showed well-differentiated neuroendocrine tumor. Patient was subjected to pancreaticoduodenectomy [Figure 4]. The histopathology studies of the surgical specimen showed the presence of neuroendocrine tumor from the duodenum extending transmurally and infiltrating into the pancreas [Figure 5]. Perineural invasion was seen. One of the peripancreatic lymph nodes showed metastasis. Immunopathology stained positive for synaptophysin (95\%), chromogranin (90\%), cytokeratin (90\%), and CD56 (90\%) with a proliferative index of 3\% [Figure 6]. The histopathology and immunopathology confirmed the presence of a well-differentiated neuroendocrine tumor Grade 2.

Patient tolerated the procedure of pancreaticoduodenectomy without any complications and is symptomatically better and has also put on weight.

This is an open access article distributed under the terms of the Creative Commons Attribution-NonCommercial-ShareAlike 3.0 License, which allows others to remix, tweak, and build upon the work non-commercially, as long as the author is credited and the new creations are licensed under the identical terms.

For reprints contact: reprints@medknow.com

How to cite this article: Adarsh CK, Kiran R, Patil M. Tumour of the lowest probability. J Dig Endosc 2016;7:62-4. 


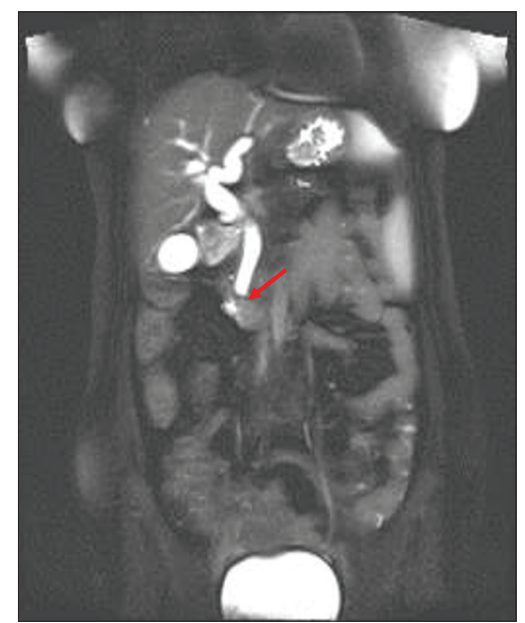

Figure 1: Magnetic resonance cholangiopancreatography showing soft tissue lesion at the terminal bile duct

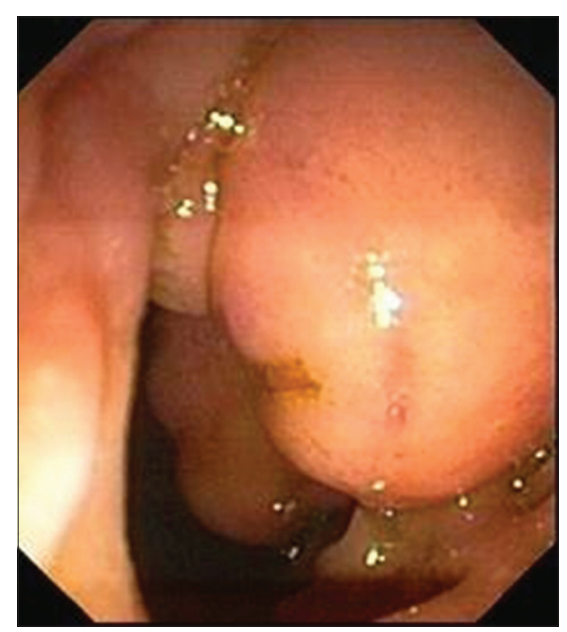

Figure 3: Side viewing endoscopy showing bulky ampulla

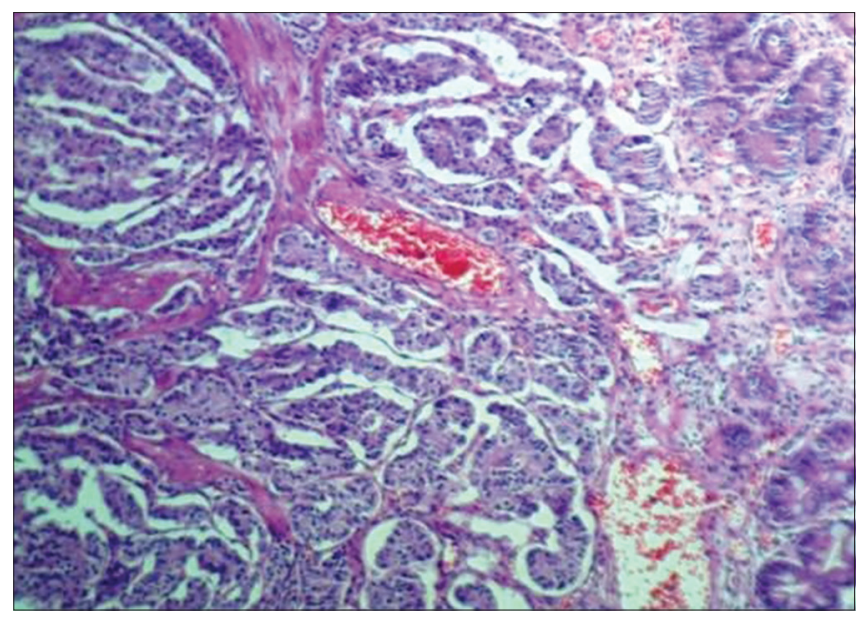

Figure 5: Neoplastic cells displaying round nuclei, fine chromatin and abundant granular eosinophilic cytoplasm $(\times 40)$

\section{Discussion}

Medical literature on the ampullary carcinoid is scarce. Most of the literature available is in the form of case reports. While Journal of Digestive Endoscopy Vol 7 | Issue 2 | April-June 2016

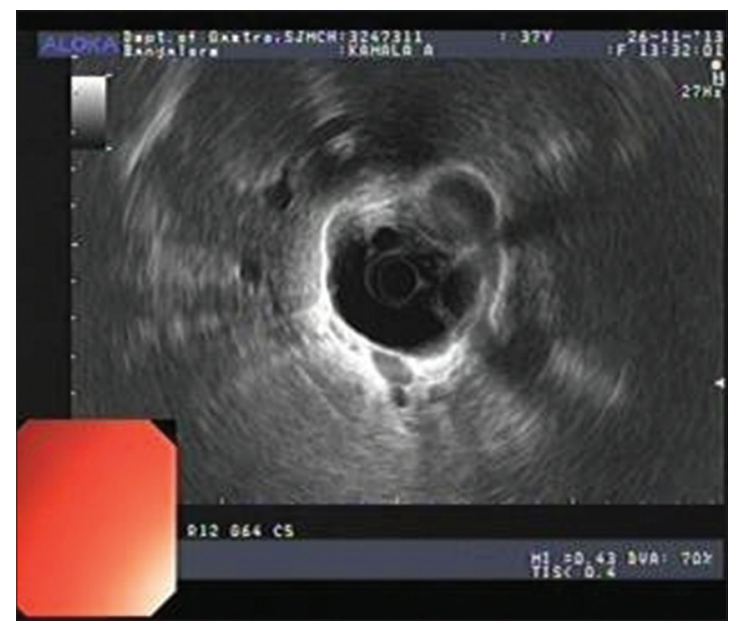

Figure 2: Endoscopic ultrasound showing soft tissue lesion at the terminal common bile duct

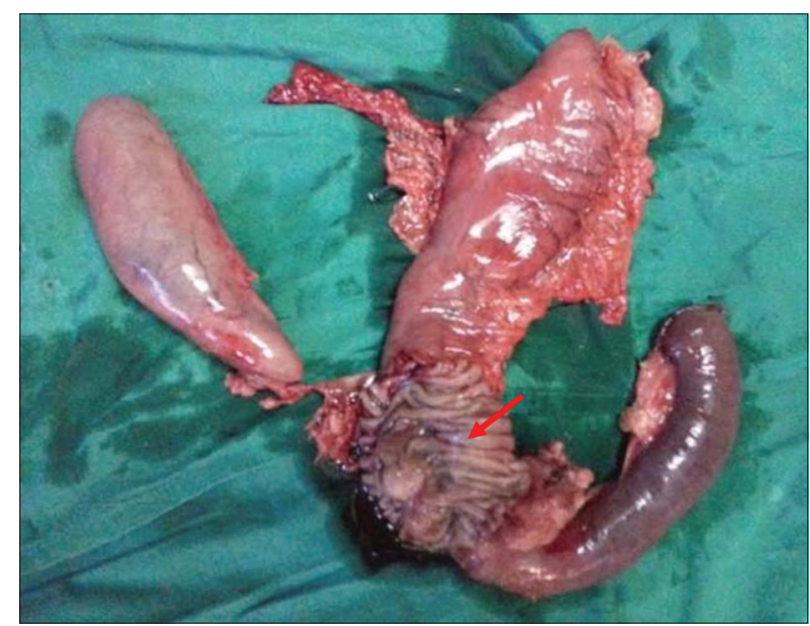

Figure 4: Resected Whipple's Specimen

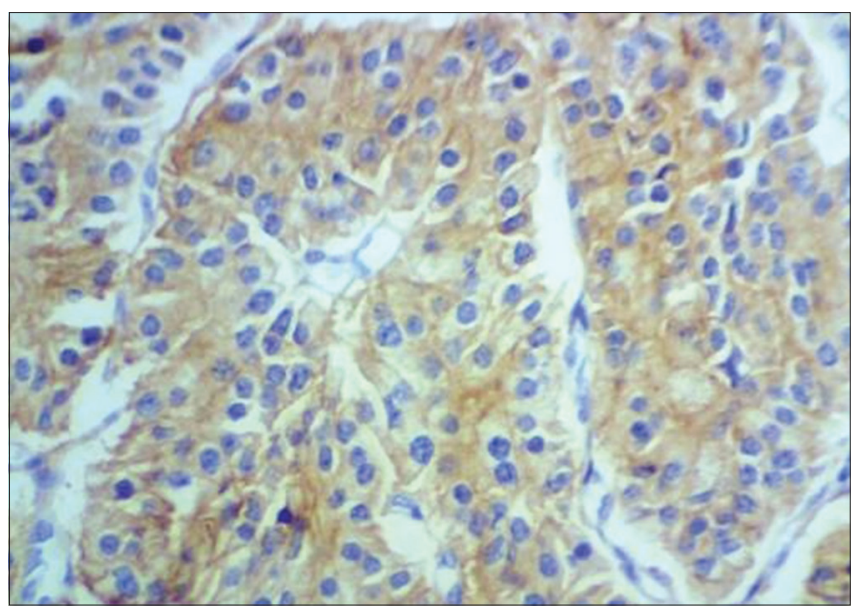

Figure 6: CD56 immunohistochemical stain showing diffuse membranous and cytoplasmic staining $(\times 40)$

the carcinoids of the duodenum are regarded as rare (2\%), the ampullary carcinoids are even rare (0.5\%). ${ }^{[1]}$ About $25 \%$ of the cases of ampullary carcinoids are seen in relation with von Reckling Hausen's syndrome and multiple endocrine 
neoplasia syndrome. Age of presentation is between 21 and 86 years. It is more common in females than males. Patients can present with jaundice $(53.1 \%)$, pain $(24 \%)$, pancreatitis $(6 \%)$, or weight loss. ${ }^{[2]}$ Preoperative diagnosis is possible in only $14 \%$ of the patients. ${ }^{[3]}$ The reason of rarer preoperative diagnosis being submucosal positioning of the tumor and the need for deeper biopsies. Duodenoscopy and endoscopic retrograde cholangiopancreatography is the diagnostic method of choice and need for deeper biopsies should be stressed upon. EUS/ magnetic resonance imaging helps in better characterization of the lesion and to know the vascular invasion. ${ }^{[4]}$ The validity of somatostatin scintigraphy in the diagnosis of ampullary NET is still debatable though it has been found to be sensitive for GI carcinoids and metastasis. ${ }^{[5]}$

It is challenging to decide the optimal treatment for ampullary carcinoids given the small number of cases studied till date. The classical Kausch-Whipple procedure or pylorus-preserving pancreaticoduodenectomy are considered to be the treatment of choice for ampullary carcinoids $>2.0 \mathrm{~cm} .{ }^{[6]}$ In cases with high cardiopulmonary comorbidity and especially in tumors $<2 \mathrm{~cm}$, local excision might be a good alternative approach. Alternatively, in patients with very high comorbidity or age, conservative treatment or minimally invasive endoscopic papillotomy should be taken into consideration. ${ }^{[7]}$

The lack of sufficient data also makes it difficult to track the prognosis of the tumor. However, in all published cases with carcinoids of the ampulla of Vater, the size of the tumor has no prognostic implication. The prognosis is reported to be excellent, with an overall 5 years survival rate of $90 \%$. In contrast to duodenal carcinoids, a correlation between mitotic activity and metastatic potential is not found. ${ }^{[8]}$

\section{Conclusion}

Neuroendocrine tumors of the ampulla, though rare, can be diagnosed accurately and has a good prognosis as shown in our patient with appropriate treatment strategies.

\section{Financial support and sponsorship}

Nil.

\section{Conflicts of interest}

There are no conflicts of interest.

\section{References}

1. Warren KW, McDonald WM, Logan JH. Periampullary and duodenal carcinoid tumours. Gut 1964;5:448-53.

2. Hartel M, Wente MN, Sido B, Friess H, Büchler MW. Carcinoid of the ampulla of Vater. J Gastroenterol Hepatol 2005;20:676-81.

3. Hatzitheoklitos E, Büchler MW, Friess H, Poch B, Ebert M, Mohr W, et al. Carcinoid of the ampulla of Vater. Clinical characteristics and morphologic features. Cancer 1994;73:1580-8.

4. Müller MF, Meyenberger C, Bertschinger P, Schaer R, Marincek B. Pancreatic tumors: Evaluation with endoscopic US, CT, and MR imaging. Radiology 1994;190:745-51.

5. Krenning EP, Kwekkeboom DJ, Bakker WH, Breeman WA, Kooij PP, Oei HY, et al. Somatostatin receptor scintigraphy with [111In-DTPA-D-Phe1]-and [123I-Tyr3]-octreotide: The Rotterdam experience with more than 1000 patients. Eur J Nucl Med 1993;20:716-31.

6. Ricci JL. Carcinoid of the ampulla of Vater. Local resection or pancreaticoduodenectomy. Cancer 1993;71:686-90.

7. Zyromski NJ, Kendrick ML, Nagorney DM, Grant CS, Donohue JH, Farnell MB, et al. Duodenal carcinoid tumors: How aggressive should we be? J Gastrointest Surg 2001;5:588-93.

8. Makhlouf HR, Burke AP, Sobin LH. Carcinoid tumors of the ampulla of Vater: A comparison with duodenal carcinoid tumors. Cancer 1999;85:1241-9. 